\title{
Gastrointestinal complications of gastrocystoplasty
}

\author{
B D Gold, P S Bhoopalam, R M Reifen, E Harvey, M A Marcon
}

\begin{abstract}
The cases are reported of five children with chronic renal failure who underwent gastrocystoplasty for a variety of urological disorders. Gastrocystoplasty comprises the transplantation of a vascularised segment of stomach to the bladder to form an augmented neobladder. The patients had gastrointestinal complications after the operation, including considerable weight loss in all five patients, accompanied by marked failure to thrive in four of the five patients, and food aversion, feeding intolerance, dumping syndrome, delayed gastric emptying, and oesophagitis in two patients. Three of the five patients developed severe abdominal pain and haemorrhagic cystitis secondary to gastric acid secretion in the neobladder from the transplanted gastric pedicle. Nutritional and pharmacological interventions were used to manage the gastrointestinal problems. Explanations are offered for the pathophysiology of the observed complications of gastrocystoplasty. It is believed that the use of this procedure in infants and children, particularly those with chronic renal failure and uraemia, warrants caution until successful long term follow up and experience with this procedure have been reported.
\end{abstract}

\section{(Arch Dis Child 1992;67:1272-6)}

Gastrocystoplasty is a technique that uses a vascularised segment of the stomach to replace or augment the urinary bladder. The more common use of ileal, caecal, jejunal, and colonic segments for this purpose has been well described. $^{12}$ Two major series have been reported for the use of gastrocystoplasty in children. ${ }^{34}$ Bladder augmentation is most often used after cystectomy in adults who have tuberculosis of the bladder or bladder carcinoma, ${ }^{1}$ and in children who have urodynamic dysfunction (such as neurogenic bladder or bladder outlet obstruction). ${ }^{15-7}$ The most common urodynamic disorder in children that requires bladder augmentation is a trabeculated, low compliance bladder, which often occurs in boys with posterior urethral valves and chronic vesicoureteral reflex. ${ }^{8}$

Owing to the potential metabolic disturbances $^{9}$ and nutritional consequences of using bowel segments, ${ }^{10}$ the use of stomach segments for bladder augmentation has been suggested. Although this technique has been studied in two types of animal model, ${ }^{11}$ the complications of this operation in children and adults have not been described. This paper describes the gastro- intestinal complications after gastrocystoplasty in five children and addresses the management of these patients.

\section{Case reports}

Gastrocystoplasty, as a form of bladder augmentation and an alternative to more conventional bladder augmentation techniques, was performed on five children with different urological dysfunctions at The Hospital for Sick Children, Toronto, Ontario, from 1987 to 1991. This operation comprised $5 \%$ of the total of 90 bladder augmentations performed at our institution during this period. These five children (three boys, two girls) ranged in age from 20 to 84 months. All five children had chronic renal impairment, and two were receiving haemodialysis at the time of the operation. The patients reported no underlying gastrointestinal or nutritional symptoms before gastrocystoplasty. All five patients had failure to thrive four to six months after gastrocystoplasty.

\section{PATIENT 1}

A 10 month old girl with urogenital sinus anomaly, cloacal extrophy, dysplastic kidneys, and a small bladder, which led to her initial bladder augmentation, a gastrocystoplasty, subsequently developed intermittent acidosis and alkalosis, and continued to have a low compliance, low volume bladder necessitating a second bladder augmentation, this time an ileocystoplasty. Nissen fundoplication was also performed during the ileocystoplasty because she developed refractory gastro-oesophageal reflux after gastrocystoplasty. Four months after the operation she developed cyclic vomiting, dumping syndrome, and food aversion. Investigations included an upper gastrointestinal series, a technetium-99 gastric emptying scan, a feeding study with fluoroscopy, preprandial and postprandial blood glucose monitoring, and upper endoscopy with biopsy sampling. Table 1 lists the findings and therapeutic interventions. ${ }^{12}$ After treatment, her dumping syndrome and food aversion resolved, and the patient showed appropriate weight gain.

\section{PATIENT 2}

A 54 month old boy with a small non-compliant bladder, who was receiving haemodialysis for renal failure secondary to posterior urethral valves, became anephric at gastrocystoplasty. After the operation he had severe abdominal pain, dysuria, haematuria, and hyperchloraemic
555 University Avenue, Toronto

Ontario, Canada M5G 1X8. Accepted 21 June 1992 
Table 1 Renal function, weight before and after surgery, and findings and treatment after gastrocystoplasty

\begin{tabular}{|c|c|c|c|c|c|}
\hline Data & Patient 1 & Patient 2 & Patient 3 & Patient 4 & Patient 5 \\
\hline $\begin{array}{l}\text { Glomerular filtration } \\
\text { rate } \\
\left(\mathrm{ml} / \mathrm{min} / 1 \cdot 73 \mathrm{~m}^{2}\right)^{*}\end{array}$ & 35 & $<10$ (prenephrectomy) & $<10$ & 17 & 45 \\
\hline $\begin{array}{l}\text { Weight }(\mathbf{k g}) \\
\text { before/aftert } \\
\text { surgery }\end{array}$ & $7 \cdot 9 / 7 \cdot 4$ & $12 \cdot 6 / 11 \cdot 6$ & $18 \cdot 0 / 17 \cdot 0$ & $15 \cdot 5 / 14 \cdot 7$ & $17 \cdot 8 / 16 \cdot 0$ \\
\hline Findings & $\begin{array}{l}\text { Rapid gastric emptying, } \\
\text { postprandial } \\
\text { hyper/hypoglycaemia, } \\
\text { endoscopy showed short } \\
\text { straight stomach and } \\
\text { antrum absent, normal } \\
\text { biopsy samples }\end{array}$ & $\begin{array}{l}\text { Haemorrhagic cystitis } \\
\text { acidic intrabladder pH }\end{array}$ & $\begin{array}{l}\text { Normal to rapid gastric } \\
\text { emptying, small } \\
\text { stomach, narrow } \\
\text { deformed antrum, mild } \\
\text { gastritis, severe } \\
\text { oesophagitis }\end{array}$ & $\begin{array}{l}\text { Haemorrhagic cystitis, } \\
\text { acidic intrabladder } \mathrm{pH}\end{array}$ & $\begin{array}{l}\text { Haemorrhagic cystitis, } \\
\text { acidic urine pH }\end{array}$ \\
\hline Treatment & $\begin{array}{l}\text { Small frequent feedings } \\
\text { by mouth, addition of } \\
\text { cornstarch and medium } \\
\text { chain triglyceride oil, } \\
\text { continuous nasogastric } \\
\text { overnight feeds, } \\
\text { daytime nasogastric } \\
\text { bolus feeds }\end{array}$ & $\begin{array}{l}\text { Bladder irrigation with } \\
\text { bicarbonate, ranitidine, } \\
\text { omeprazole }\end{array}$ & $\begin{array}{l}\text { Short term total parenteral } \\
\text { nutrition, cisapride and } \\
\text { ranitidine }\end{array}$ & $\begin{array}{l}\text { Bladder irrigation with } \\
\text { bicarbonate, ranitidine }\end{array}$ & Omeprazole \\
\hline
\end{tabular}

*Approximate glomerular filtration rate calculated with the Schwartz method; values given are for before the gastrocystoplasty (reference normal value at this institution $\left.>100 \mathrm{ml} / \mathrm{min} / 1 \cdot 73 \mathrm{~m}^{2}\right) .13$

†Four to six months after gastrocystoplasty.

alkalosis. Investigations included cystoscopy, and intragastric and intrabladder $\mathrm{pH}$ measurements. His suprapubic pain was consistently associated with a bladder $\mathrm{pH}$ of less than 2 , and the resolution of symptoms was associated with an increase in bladder $\mathrm{pH}$ (table 2). He initially received ranitidine and intrabladder bicarbonate irrigation, but the $\mathrm{pH}$ decreased two hours after bicarbonate irrigation and his symptoms resumed (tables 1 and 2). Sucralfate bladder irrigation was not successful because of intrabladder concretions. Treatment with omeprazole gave a resolution of symptoms, maintenance of normal intrabladder $\mathrm{pH}$, and an increase in intragastric $\mathrm{pH}$ (table 2), with an increase of gastrin in serum samples to $3105 \mathrm{ng} / \mathrm{l}$ (reference range $0-75 \mathrm{ng} / \mathrm{l}$ ). He has gained weight appropriately, but has required maintenance treatment with omeprazole for symptomatic relief despite renal transplantation and a glomerular filtration rate of $74 \mathrm{ml} / \mathrm{min} / 1 \cdot 73 \mathrm{~m}^{2}$.

\section{PATIENT 3}

A 62 month old boy with a small non-compliant bladder, who was receiving haemodialysis for renal failure secondary to posterior urethral valves, underwent an unsuccessful gastrocystoplasty and subsequent ileocystoplasty. He subsequently developed food aversion, nausea, vomiting, and early satiety, in addition to hypoalbuminaemia (albumin concentration 24 g/l) without significant proteinuria. Investigations included upper gastrointestinal series and upper endoscopy with biopsy sampling (table 1). The patient gained weight adequately after therapeutic intervention and had no additional gastrointestinal disorders at follow up.

\section{PATIENT 4}

Four months after gastrocystoplasty for a neurogenic bladder this 80 month old boy with Vater association developed abdominal pain and haematuria. Investigations included cystoscopy and intrabladder $\mathrm{pH}$ measurements (tables 1 and 2). This patient did not receive omeprazole as he found his symptoms tolerable with ranitidine and intrabladder bicarbonate irrigation (table 2). Six months after treatment had begun it was discontinued without recurrence of symptoms.

\section{PATIENT 5}

A 40 month old girl with urogenital sinus anomaly, high cloacal anomaly, anomalous ureteric implantation, small kidneys, and a small bladder, underwent gastrocystoplasty during genitourinary tract reconstruction. Three months after her gastrocystoplasty, she developed severe lower abdominal pain and bladder spasm, with symptoms intensifying 30 minutes to one hour postprandially. Neither cystoplasty nor other investigations were performed. Omeprazole (10 mg/day) successfully resolved her symptoms; her urine $\mathrm{pH}$ three days after treatment with omeprazole was $4 \cdot 2$. A pH

Table 2 Intrabladder and intragastric $\mathrm{pH}$ before and after treatment

\begin{tabular}{lll}
\hline$p H$ & Patient 2 (anuric) & Patient 4 \\
\hline $\begin{array}{l}\text { Intrabladder } \mathrm{pH}^{*} \text { before treatment } \\
\text { Intrabladder pH one hour after bladder } \\
\text { irrigation with bicarbonate }\end{array}$ & $\begin{array}{l}0 \cdot 5-2 \cdot 0 \text { with GI and GU symptoms } \\
5 \cdot 5-8 \cdot 0 \text { without symptoms }\end{array}$ & $\begin{array}{l}1 \cdot 0-1 \cdot 5 \text { with GI and GU symptoms } \\
6 \cdot 0-7 \cdot 5 \text { without symptoms }\end{array}$ \\
$\begin{array}{c}\text { Intrabladder pH two hours after bladder } \\
\text { irrigation with bicarbonate }\end{array}$ & $1 \cdot 5-2 \cdot 0$ with GI and GU symptoms & $2 \cdot 5-3 \cdot 0$ with minimal symptoms \\
$\begin{array}{c}\text { Intrabladder pH after treatment with } \\
\text { omeprazole }\end{array}$ & $5 \cdot 0-7 \cdot 0$ without symptoms & Not applicable \\
$\begin{array}{c}\text { Intragastric pH after treatment with } \\
\text { omeprazole }\end{array}$ & $4 \cdot 5-6 \cdot 0$ & Not applicable
\end{tabular}


value for urine free of omeprazole has not been obtained. She is still being treated with omeprazole for symptomatic relief after two unsuccessful attempts to discontinue the drug.

\section{Discussion}

Although bladder augumentation with part of the gastrointestinal tract was described nearly 100 years ago, ${ }^{5}$ descriptions of the sequelae of this procedure, particularly gastrointestinal tract complications, have been difficult to find. Furthermore, bladder augmentation effects on nutritional status have only recently been reported showing no long term changes in vitamin B-12, carotene, and albumin concentrations. ${ }^{10}$ Metabolic complications after enterocystoplasty, such as chronic acidosis and rickets, have been described in children, ${ }^{14}$ and hyperchloraemic metabolic acidosis and diminished acid challenge capacity have been described in children and animal models of bladder augmentation.9 911

Using a canine bladder augmentation model, Piser $e t$ al showed a net reabsorption of chloride, ammonia, phosphate, and sodium in animals who underwent colocystoplasty compared with those who underwent gastrocystoplasty. ${ }^{11}$ Guan et al, using Long-Evans rat species, studied the short and long term effects of ileal, colonic, and gastric segment cystoplasties. ${ }^{15}$ They found that all voiding parameters, renal function, and biochemical profiles remained normal; levels of mucus production in the neobladder were higher in patients with gastrocystoplasty and colocystoplasty than in those with ileocystoplasty; and uroepithelialisation of the graft occurred, with native transitional epithelium extending over the junctional margin of the graft and covering the enteropatch mucosa as seen at necropsy.

The effect of chronic renal failure on bladder augmentation with stomach rather than sigmoid colon segments has been reviewed in the canine study by Kennedy et al. ${ }^{16}$ Their results indicate that gastrocystoplasty is a superior technique for the treatment of the azotaemic canine. These animals tolerated significantly greater acid loading and did not have the hyperchloraemic acidosis and weight loss of the other animals who underwent enterocystoplasty.

Reports of bladder augmentation in children, including gastrocystoplasty, have not addressed the gastrointestinal complications that seem physiologically inherent in this procedure. Adams et $a l$, in the largest series to date, described 10 patients undergoing gastrocystoplasty who had no sequelae or complications. ${ }^{17}$ Follow up however, occurred only at one and three months, less than the average follow up interval (five months) for our series, at which time complications became apparent and clinically significant. In addition, Adams et al did not measure glomerular filtration rate, a more accurate indicator of renal function, making less clear the degree of renal compromise existing in their patients before and after gastrocystoplasty. ${ }^{17}$

Two studies of animal models reported that the use of stomach segments is a viable alterna- tive and has functioned well, causing no gastrointestinal complications or genitourinary problems. ${ }^{15} 16$ Others, using a canine model, have shown that urine, or some component of urine, appears to suppress antral gastrin secretion as measured by serum gastrin concentrations and antral G cell hyperplasia. ${ }^{78}$ Lau et al showed that $4 \%$ aqueous peptone solution instilled into exteriorised antral pouches caused a significant increase in mean serum gastrin concentrations, compared with little or no change in mean serum gastrin with a $4 \%$ aqueous peptone solution in concentrated dog urine. ${ }^{18}$ Muraishi et al, however, reported a markedly decreased postprandial urine $\mathrm{pH}$ $(2 \cdot 4-4 \cdot 2)$ in six dogs undergoing gastrocystoplasty at six months' follow up. ${ }^{19}$ More importantly they found that histological erosions developed in the bladder remnant in five dogs, and an ulcer in the native bladder remnant in the sixth dog. Tiffany et al reported severe hypergastrinaemia after the operation that led to the development of gastric ulcers in dogs undergoing gastrocystoplasty. ${ }^{20}$ Renal function was not addressed in these studies.

Based on our findings for patients 2, 4, and 5 in our series, we believe that their native bladder epithelium lacked some form of cytoprotection against the normal acid production of the transplanted gastric segment. Cystoscopy in two of these patients showed haemorrhagic cystitis of the native bladder, but not of the transported gastric segment, probably the consequence of acidic urine.

Epidermal growth factor, or urogastrone, a normal constituent of canine and human urine, has been shown to inhibit gastric acid secretion after parenteral administration and is required for ongoing urinary tract epithelial growth. Horikoshi et al have shown that decreased production of epidermal growth factor and local differences of epidermal growth factor concentrations may be contributing factors to the development of dysplastic mesonephric tissue and also to normal urinary tract epithelialisation. ${ }^{21}$ It may be important to ensure quality urine production before gastrocystoplasty to provide adequate epithelialisation of the neosegment from the surrounding native bladder epithelium and thus protect it from acid secretion. Inadequate amounts, low concentrations, or inactivation of growth factors, or lack of some other factors may have contributed to the bladder pathology. ${ }^{22} 23$ Lack of cytoprotection may explain why patients 2 and 4 , who had comparable glomerular filtration rates, developed similar cystoscopic and clinical findings, compared with patient 1 , who had a significantly better glomerular filtration rate and who developed none of the observed complications. Patient 5, however, was symptomatic and had clinical evidence of haemorrhagic cystitis and an acid urine $\mathrm{pH}$ early in the course of her treatment, despite a glomerular filtration rate similar to that of patient 1 . The difference in quality of urine production in patients 1 and 5, resulting in one patient developing symptoms and the other not, may eventually be explained when the cytoprotection factors in urine can be evaluated. 
Neutralisation of acid urine provided relief in all patients. Bladder irrigation with bicarbonate alleviated symptoms, but its effect was short lived and the procedure time consuming. Patients 2 and 4 had inadequate relief of symptoms with $\mathrm{H}_{2}$ blockers and required treatment with omeprazole. Omeprazole is the first of a new class of drugs that inhibit gastric secretion by altering the activity of hydrogen/ potassium ATPase. ${ }^{24}$ This drug has been used in a variety of patients for whom hyperacidity is a major problem (for example, Zollinger-Ellison syndrome) and who have been refractory to more conventional $\mathrm{H}_{2}$ blockers or antacids. ${ }^{26}$

Studies have implicated the long term use of omeprazole in gastric carcinoma in rats, secondary hypergastrinaemia, and hyperplasia of enterochromaffin cells. ${ }^{24}$ In one study of the long term effects of gastrocystoplasty in rats, ${ }^{27}$ follow up 18 months after the operation showed prominent histopathological changes of the bladder in the gastrocystoplasty group, ranging from atrophy of glands in the gastric patch, to tumours of the mucosal surface. Patients who are at risk for development of cancer because of immunosuppression after renal transplant may develop dysplastic changes in the bladder epithelium from long term exposure to an acid environment. We therefore believe that any patient undergoing gastrocystoplasty should be monitored with regular cystoscopy. Furthermore, these patients may also require long term treatment with omeprazole, which may further enhance their risk of developing a malignancy.

Patients with chronic renal failure may be at greater risk for gastrointestinal complications from gastrocystoplasty. Uraemia and chronic renal failure have often been reported as causes of gastrointestinal symptoms such as nausea, vomiting, anorexia, and poor weight gain. These symptoms may be aggravated by gastric surgery. ${ }^{28}$

Descriptions of the animal model of gastrocystoplasty report the surgical excision of only a small segment of stomach from the gastric antrum to form the augmented neobladder. ${ }^{3}$ Too small a gastric flap often results in inadequate bladder augmentation. Conversely, the larger the gastric segment the greater the risk for developing gastrointestinal complications. ${ }^{429}$ Therefore, patient size and age may be important factors in assessing suitability for this procedure.

Gastrectomy, which alters gastric motility and changes gastric compliance, probably resulted in the symptoms experienced by patients 1 and 3 , namely, vomiting, dumping syndrome and food aversion, ${ }^{30} 31$ nausea and early satiety, and failure to thrive. The dumping syndrome of patient 1 was eventually alleviated by the addition of medium chain triglyceride oil and cornstarch to Peptamen (Carnation) delivered through a nasogastric tube to delay gastric emptying. ${ }^{13}$ The severe oesophagitis observed in patient 3 was probably avoided in patient 1 by the antireflux procedure (Nissen fundoplication) performed after the gastrocystoplasty. We are not, however, advocating this as a concurrent procedure in all patients undergoing gastrocystoplasty as Nissen fundoplication may be accompanied by complications such as rapid gastric emptying and dumping syndrome. ${ }^{30}$ The food aversion of patient 3 was probably due to severe oesophagitis. ${ }^{30} 32 \mathrm{With}$ conventional treatment (cisapride, ranitidine, and a high carbohydrate, low fat diet), we were able to alleviate his symptoms.

In summary, there are considerable gastrointestinal complications associated with gastrocystoplasty. As a result of the complications observed in all of our patients who have undergone gastrocystoplasty, we believe that the use of this procedure for bladder augmentation in infants and children, particularly those with chronic renal failure, warrants caution. Future research should focus on animals with previously induced chronic renal failure. Only after long term follow up and more extensive experience with gastrocystoplasty in children will we be able to evaluate the viability of gastrocystoplasty as an alternative to more conventional techniques for bladder augmentation.

This paper was prepared with the assistance of Medical Publications, The Hospital for Sick Children, Toronto, Ontario, Canada.

1 Smith RB, Van Cangh P, Skinner DG, Kaufman JJ, Goodwin WE. Augmentation enterocystoplasty: a critical review. F Urol 1977;118:35-9.

2 Wenderoth UK, Ruediger B, Egghart G, Frohneberg D, Miller K, Hautmann RE. The ileal neobladder: experience and results of more than 100 consecutive cases. $\mathcal{F}$ Uro 1990; 143:492-7.

3 Kass EJ, Koff SA. Bladder augmentation in the pediatric neuropathic bladder. F Urol 1983;129:552-5.

4 Hendren WH, Hendren RB. Bladder augmentation: experience with 129 children and young adults. $f$ Urol 1990;144:445-53.

5 Mikulicz J. Zur operation der angeborenen Blasenpalte. Zentralbl Chir 1899;26:641-50.

6 Lapides J, Diokno AC, Silber SJ, Lowe BS. Clean, intermittent self-catherization in the treatment of urinary tract mittent self-catherization in the

7 Sinaiko E. Artificial bladder from segment of stomach and study of effect of urine on gastric secretion. Surg Gynecol Obstet 1956;102:433-8.

8 Decter RM, Bauer SB, Mandell J, Colodny AH, Retik AB. Small bowel augmentation in children with neurogenic bladder: an initial report of urodynamic findings. $\mathcal{F}$ Uro 1987;138:1014-6.

9 Koch MO, McDougal WS. The pathophysiology of hyperchloremic metabolic acidosis after urinary diversio through intestinal segments. Surgery 1985;98:561-70.

10 Canning DA, Perman JA, Jeffs RD, Gearhart JP. Nutritional consequences of bowel segments in the lower urinary tract.

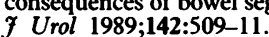

11 Piser JA, Mitchell ME, Kulb TB, Rink RC, Kennedy HA McNulty A. Gastrocystoplasty and colocystoplasty in canines: the metabolic consequences of acute saline and canines: the metabolic consequences of

12 Khoshoo V, Reifen RM, Gold BD, Sherman PM, Penchar PB. Nutritional manipulation in the management of PB. Nutritional manipulation in the management
dumping syndrome. Arch Dis Child 1991;66:1447-8.

13 Schwartz GJ, Brion LP, Spitzer A. The use of plasma creatinine concentration for estimating glomerular filtration rate in infants, children, and adolescents. Pediatr Cli North $A m$ 1987;34:571-90.

14 Boyd JD. Chronic acidosis secondary to ureteral transplantation. Am $\mathcal{J}$ Dis Child 1931;42:366-71.

15 Guan Z, Ricard G, Charest-Boulé L, Neilson K, Kiruluta G Augmentation cystoplasty in rats: development of an animal model. F Urol 1990;144:461-5.

16 Kennedy HA, Adams MC, Mitchell ME, Rink RC, Piser JA McNulty A. Chronic renal failure and bladder augmentation: stomach versus sigmoid colon in the canine model. $\mathcal{f}$ Urol 1988;140:1138-40.

17 Adams MC, Mitchell ME, Rink RC. Gastrocystoplasty: an alternative solution to the problem of urologic reconstruction in the severely compromised patient. $\mathcal{f}$ Urol 1988; 140:1152-6.

18 Lau JL, Richter HM III, Fowler JE Jr, Bhatti R, Ray V. Suppression of canine antral gastrin secretion by urine. I Urol 1990;143:402-6.

19 Muraishi O, Ikado S, Yamashita T, Yamaguchi K, Ogawa A Gastrocystoplasty in dogs: an ulcerating effect of acid urine. 7 Urol 1992;147:242-5. 
20 Tiffany P, Vaughan ED Jr, Marion D, Amberson J. Hypergastrinemia following antral gastrocystoplasty. F Urol 1986;136:692-5.

21 Horikoshi S, Kubota S, Martin GR, Yamada Y, Klotman PE Epidermal growth factor (EGF) expression in the congenital polycystic mouse kidney. Kidney Int 1991;39:57-62.

22 Avner ED, Piesco NP, Sweeney WE, Ellis D. Renal epithelial development in organotypic culture. Pediatr Nephrol 1988;2:92-8.

23 Fisher DA, Lákshmanan J. Metabolism and effects of epidermal growth factor and related growth factors in epidermal growth factor and related growth factors

Ecr Rev 199,11:418

24 Maton PN. Omeprazole. N Engl f Med 1991;324:965-75.

Rabon EC, Reuben MA. The mechanism and structure of the gastric H,K-ATPase. Annu Rev Physiol 1990;52:321-44.

26 Maton PN, Vinayek R, Frucht H, et al. Long-term efficac and safety of omeprazole in patients with Zollinger-Ellison syndrome: a prospective study. Gastroenterology 1989;97: 827-36.

27 Klee LW, Hoover DM, Mitchell ME, Rink RC. Long term effects of gastrocystoplasty in rats. $\mathcal{F}$ Urol 1990;144:1283-7. 28 Merrill JP, Hampers CL. Uremia. N Engl f Med 1970;282: 953-61.

29 MacLean LD, Rhode BM, Shizgal HM. Nutrition following gastric operations for morbid obesity. Ann Surg 1983;198: gastric ope

30 Hirsig J, Baals H, Tuchschmid P, Spitz L, Stauffer UG. Dumping syndrome following Nissen's fundoplication: a cause for refusal to feed. $\mathcal{F}$ Pediatr Surg 1984;19:155-7.

31 Caulfield ME, Wyllie R, Firor HV, Michener W. Dumping syndrome in children. $\mathcal{F}$ Pediatr 1987;110:212-5.

32 Sondheimer JM. Gastroesophageal reflux: update on pathogenesis and diagnosis. Pediatr Clin North Am 1988;35: 103-16.

\section{All Greek}

Here's a fascinating fact for you. I bet you didn't know that Greek eggs contain eight or nine times as much docosahexaenoic acid (DHA) as standard American supermarket eggs (Artemis $\mathbf{P}$ Simopoulos and Norman Salem, Jr, American fournal of Clinical Nutrition 1992;55:411-4). But then, when the fatty acid has a name like that, they would, wouldn't they? And if the author's name had been Simopollochkov they'd probably have been Russian eggs.

Studies have shown that infant formulas are lacking in such long chain polyunsaturated fatty acids which are present in human milk. DHA may be an essential nutrient as there is evidence that babies who don't get enough of it have deficient functioning of the retinal rods. Eggs are used as a source of fatty acids for infant formulas but their content of DHA varies according to how the hens were fed. American supermarket eggs were found to have a low content, eggs from hens fed on flax or on fishmeal contained more, but free range (Greek) eggs contained most of all. Other studies have shown that in plants, eggs, fish, and meat the wild or free varieties have a greater content of certain fatty acids than the cultivated or restrained. So that's another one up for the Greens. Infant feeding is so complex it's a wonder that any of us grow up to have an ounce of sense or even grow up at all (see Archivist 1991:1290). 